\title{
SEROPREVALENCIA DE Toxoplasma gondii EN ALPACAS (Lama pacos) EN UNA UNIDAD DE PRODUCCIÓN DE LA SIERRA CENTRAL DEL PERÚ
}

\author{
Seroprevalence of Toxoplasma gondi in Alpacas (Lama pacos) in a \\ Commercial Production Unit of the Central Highlands of Peru
}

\author{
Edwin Poma De la C. ${ }^{1}$, Amanda Chávez V. ${ }^{1,2}$, Eva Casas A. ${ }^{1}$, Néstor Falcón P. ${ }^{3,4}$ y
} DanielZárate R. ${ }^{1}$

\section{Resumen}

\begin{abstract}
El objetivo del presente estudio fue determinar la seroprevalencia de Toxoplasma gondii en alpacas de la Unidad de Producción Cochas de la SAIS Túpac Amaru, ubicada en el departamento de Junín. En diciembre del 2000 se recolectaron 200 muestras de sangre de alpacas de ambos sexos para la detección de anticuerpos contra T. gondii mediante la técnica de Hemaglutinación Indirecta (HAI). Los resultados indicaron que el $21 \pm 5.6 \%$ (42/200) de las muestras presentaron anticuerpos con títulos que variaron desde 1/16 hasta 1/1024. Mediante la prueba de regresión logística no se encontró asociación estadística significativa entre la presencia de anticuerpos contra $T$. gondii y el sexo de las alpacas; sin embargo, hubo diferencia con la edad del animal, siendo las alpacas jóvenes (8 a 12 meses) 2.9 veces más susceptibles que los dos grupos $>12-36$ y $>36$ meses de edad. La prevalencia encontrada en el presente estudio fue moderada.
\end{abstract}

Palabras clave : toxoplasmosis, camélidos, HAI, prevalencia, SAIS Túpac Amaru

\section{Abstract}

The aim of this study was to determine the seroprevalence of Toxoplasma gondii in alpacas from a commercial unit of SAIS Tupac Amaru, located at Junín Department. A total of 200 blood samples were collected in alpacas of both sexes for the detection of antibodies against $T$. gondii by the Indirect Hemaglutination Test (IHA). The results indicated that $21 \pm 5.6 \%(42 / 200)$ of the samples had antibodies and the titres varied from 1/16 till 1/1024. The Logistic Regression Test failed to obtain statistical relationship between the presence of $T$. gondii antibodies and the sex of the animal, but there was a significant relationship with age. Young alpacas ( 8 to 12 months of age) were 2.9 times more susceptible than the groups of $>12-36$ and $>36$ months of age. These results could

${ }^{1}$ Laboratorio de Microbiología y Parasitología Veterinaria, ${ }^{3}$ Laboratorio de Medicina Veterinaria Preventiva, Facultad de Medicina Veterinaria, Universidad Nacional Mayor de San Marcos, Lima

${ }^{2}$ E-mail: achavezvg@gmail.com

${ }^{4}$ Dirección actual: Facultad de Veterinaria y Zootecnia, Universidad Peruana Cayetano Heredia, Lima 
be due to the presence of maternal antibodies, animal management, environmental factors, and the presence of the definitive host. The prevalence found in the present study was considered as moderate.

Key words: toxoplasmosis, alpaca, IHA, seroprevalence, SAIS Tupac Amaru

\section{INTRODUCCIÓN}

La toxoplasmosis es una de las infecciones parasitarias y zoonóticas de mayor difusión en la naturaleza. Se encuentra en todas las latitudes afectando a humanos y a diversas especies de mamíferos domésticos, silvestres y aves. El agente causal es el Toxoplasma gondii, protozoario polixeno y heteroxeno facultativo (Tenter et al., 2000), que tiene como hospederos definitivos al gato y a algunos félidos silvestres como el puma, gato andino y gato montés (Acha y Szyfres, 1986).

La transmisión de esta zoonosis es principalmente por la ingestión de carne, leche, huevos crudos o mal cocidos. El hombre puede, además, infectarse por contaminación fecal y transmisión congénita (Appleford y Smith, 2000). Las infecciones por T. gondii ocurren, generalmente, en forma subclínica o asintomática y solo en forma ocasional se produce la enfermedad, mayormente en personas o animales jóvenes inmuno comprometidos y durante la preñez (Dubey y Lappin, 2000). Constituye un serio problema en la crianza de ovinos, caprinos y suinos, ya que ocasiona reabsorción embrionaria, abortos, mortalidad perinatal, e infertilidad temporal (Blood et al., 1992), siendo una de las primeras causales de aborto ovino de naturaleza infecciosa, reportándose pérdidas que pueden ir del 1 al 40\% de las gestaciones (Freyre et al., 1999).

En la evaluación de la infección toxoplásmica se han utilizado diversas pruebas inmunológicas, destacándose las reacciones de hemaglutinación e inmunofluorescencia indirecta, las que detectan anticuerpos relacionados a los constituyentes citoplasmáticos de origen proteico y anticuerpos de fracción $\mathrm{M} \mathrm{o} \mathrm{G} \mathrm{de}$ las inmunoglobulinas, respectivamente (D’angelino y Ishizuka, 1986). En el Perú, se han reportado prevalencias elevadas en varias especies de rumiantes, como es el caso de la alpaca con $24 \%$ (Góngora, 1992) y el caprino con 58\% (Vidal, 1990) en la zona sur y centro del país, respectivamente; faltando información epidemiológica de esta enfermedad en otras áreas ganaderas del país. Debido a esto, se realizó el presente estudio con el fin de estimar la seroprevalencia de $T$. gondii en alpacas de una de las principales empresas alpaqueras del centro del país.

\section{Materiales y Métodos}

El estudio se llevó a cabo en diciembre del 2000 en la Unidad de Producción de Cochas de la SAIS Túpac Amaru, situado en Jauja, departamento de Junín, a 4,065 msnm, con una precipitación pluvial anual de 500 a $950 \mathrm{~mm}$, temperatura promedio de $3-6^{\circ} \mathrm{C}$, y con vegetación herbácea rastrera y pajonales de puna (INRENA, 2000).

El tamaño mínimo muestral se determinó utilizando la fórmula para estimar una proporción (Miguel, 1982) considerando una prevalencia de 50\% (Leguía et al., 1988), un nivel de confianza del $95 \%$ y un error máximo permisible del $0.07 \%$. Se recolectaron 200 muestras de sueros de alpacas aparentemente sanas, cuyo número fue distribuido en tres grupos etáreos: 8 a $12,>12$ a 36 y >36 meses. Las muestras de sangre se colectaron en tubos vacutainers estériles y el suero resultante se almacenó en viales individuales. Los sueros se trasladaron al Laboratorio de Parasitología de la Facultad de Medicina Veterinaria de la Universidad Nacional Mayor 
de San Marcos, Lima, donde se almacenaron a $-20{ }^{\circ} \mathrm{C}$ hasta la realización de la prueba de hemoaglutinación indirecta, usando un kit comercial (Toxotest, Wiener Lab.).

Para cuantificar la asociación entre las variables sexo y grupo etáreo con la presencia de infecciones con $T$. gondii se utilizó la prueba de regresión logística (Kenneth y Sander, 1998).

\section{Resultados y Discusión}

Se encontró una seroprevalencia de Toxoplasma gondii de $21.0 \pm 5.6 \%$, confirmándose la existencia de anticuerpos contra este agente en alpacas de la Sierra Central del país. Este resultado es similar a la prevalencia de $24 \%$ reportada en Puno mediante la prueba de inmunofluorescencia indirecta (IFI) (Góngora, 1992); sin embargo, reportes donde se utilizó la técnica de HAI en Puno señalan prevalencias de 50 y $45 \%$ (Leguía et al., 1988; Gómez et al., 2003, repectivamente). Otros estudios realizados con esta técnica en el norte de Chile encontraron valores diversos; así, Rojas et al. (1989) encontraron una prevalencia de $T$. gondii de $47 \%$ en machos y $24 \%$ en hembras, mientras que Gorman et al. (1999) reportaaron una prevalencia de $16 \%$.

La variedad de resultados obtenidos por diversos autores estaría relacionada a factores tales como tipo de explotación, ubicación geográfica, altitud, cercanía de fuentes de agua, factores ambientales, presencia del hospedero definitivo (felinos domésticos y silvestres), y la técnica diagnóstica utilizada (Luzón et al., 1997). Así mismo, incluso en áreas que podrían ser consideradas endémicas, el carácter esporádico de la infección suele implicar grandes diferencias entre una explotación y otra, así como entre un año y otro, por lo que las prevalencias detectadas en una zona y época no son fácilmente extrapolables (Luzón et al., 1997).
La seroprevalencia encontrada en el presente estudio (21.0\%) es inferior a la reportada por Leguía et al. (1988) en la zona sur del país (50\%), por lo que se podría decir que corresponde a una prevalencia moderada; probablemente debido al escaso número de felinos domésticos en la zona en estudio. No obstante, no se descarta la existencia de gatos domésticos vagabundos (cimarrones) y silvestres como el gato montés andino y el puma. En el estudio de Góngora (1992), en la zona de Puno se encontró que el $95 \%$ de los animales positivos pertenecían a productores que criaban gatos; y el 5\% a aquellos que no los criaban; lo que demuestra claramente la relación entre presencia de gatos e infección.

La prueba de regresión logística indicó que el grupo etáreo de 8 a 12 meses tuvo mayor riesgo de contraer toxoplasmosis que los otros grupos etáreos $(\mathrm{p}<0.05)($ Cuadro 1$)$. Este resultado es inusual debido a que la mayoría de estudios realizados en alpacas y en otras especies muestran una tendencia de incremento de la prevalencia de anticuerpos de acuerdo a la edad; lo cual es esperado, toda vez que a mayor edad existe un mayor tiempo de exposición al agente infeccioso y la probabilidad de infectarse es mayor (Barberan y Marco, 1997). Este resultado podría deberse al manejo de los animales, ya que las alpacas hembras preñadas se encuentran en las zonas más bajas, principalmente en los bofedales (Sumar y Huanca, 1988); además, el destete se realiza entre los 8 a 9 meses, edad a la que son trasladados a otra zona de pastoreo donde probablemente se pudieron infectar. Por otro lado, se tiene entendido, que ovejas jóvenes $\mathrm{y}$ adultas son igualmente receptivas a infección por $T$. gondii, siempre que se trate de una primoinfección y dado que la forma adquirida suele proceder de la ingestión de alimentos contaminados con ooquistes, esta podría tener lugar desde el destete (Barberan y Marco, 1997). 
Cuadro 1. Seroprevalencia de Toxoplasma gondii en alpacas de la Unidad de Producción Cochas de la SAIS Túpac Amaru, distribuida según grupo etáreo (Junín, 2000)

\begin{tabular}{cccc}
\hline $\begin{array}{c}\text { Edad } \\
\text { (meses) }\end{array}$ & $\begin{array}{c}\text { Animales } \\
\text { muestreados }\end{array}$ & $\begin{array}{c}\text { Animales } \\
\text { positivos }\end{array}$ & $\begin{array}{c}\text { Prevalencia ? I.C. }{ }^{1} \\
(\%)\end{array}$ \\
\hline 8 a 12 & 33 & 11 & 33.3 \\
$>12$ a 36 & 52 & 8 & 15.4 \\
$>36$ & 115 & 23 & 20.0 \\
\hline Total & 200 & 42 & $21.0 ? 5.6$ \\
\hline
\end{tabular}

${ }^{1}$ Intervalo de Confianza del 95\%

Cuadro 2. Títulos de anticuerpos contra Toxoplasma gondii mediante la prueba de hemaglutinación indirecta en alpacas de la Unidad de Producción Cochas de las SAIS Túpac Amaru (Junín, 2000)

\begin{tabular}{cccccccccc}
\hline \multirow{2}{*}{$\begin{array}{c}\text { Grupo } \\
\text { etáreo } \\
\text { (meses) }\end{array}$} & \multicolumn{6}{c}{$\mathrm{N}^{\circ}$ de alpacas } & \multicolumn{6}{c}{ Distribución de alpacas por tít ulos de anticuerpos } \\
\cline { 2 - 10 } & Total & Positivos & $1 / 16$ & $1 / 32$ & $1 / 64$ & $1 / 128$ & $1 / 256$ & $1 / 512$ & $1 / 1024$ \\
\hline $8-12$ & 33 & 11 & 6 & 0 & 3 & 0 & 0 & 0 & 2 \\
$>12-36$ & 52 & 8 & 4 & 1 & 1 & 0 & 2 & 0 & 0 \\
$>36$ & 115 & 23 & 5 & 2 & 4 & 3 & 6 & 2 & 1 \\
\hline Total & 200 & 42 & 15 & 3 & 8 & 3 & 8 & 2 & 3 \\
\hline
\end{tabular}

En el Cuadro 2 se observa que 13 animales presentaron títulos iguales o superiores a $1 / 256$, lo que podría indicar que hubo una exposición reciente al agente infeccioso por parte de estos animales, probablemente 1 a 2 meses antes del muestreo. Lamentablemente, no se hizo un análisis con 2mercaptoetanol para inactivar IgM y poder precisar si la infección era reciente o crónica. Los títulos de significancia diagnóstica de la prueba HIA no son conocidos en las alpacas, pero se menciona que títulos de 1/ 200 en ovinos son indicativos de exposición pasada (Blewett et al., 1983); en tanto que en humanos, se considera títulos bajos (1/641/128) como exposición pasada, títulos medios (1/256 a 1/512) como infección reciente y títulos altos (1/1024) como infección aguda (Mackie et al., 1971). Si se compara estas interpretaciones con los resultados del presente estudio, indicaría que estos animales estuvieron frente a una infección reciente.

El sexo de la alpaca, según la prueba de Regresión Logística no mostró diferencia estadística y, por lo tanto, no se le puede considerar como un factor de riesgo, de modo que tanto las hembras como los machos son probables a infectarse por igual. 


\section{Conclusiones}

? La seroprevalencia de Toxoplasma gondii en alpacas de la Unidad de Producción Cochas de la SAIS Túpac Amaru fue de $21.0 \pm 5.6 \%$.

? El grupo etáreo de 8 a 12 meses presentó el mayor riesgo de infección que los otros grupos de edades.

? El sexo no constituye un factor de riesgo para contraer la infección por $T$. gondii

\section{Limeratura Citada}

1. Acha P, Szyfres B. 2003. Zoonosis y enfermedades transmisibles comunes al hombre y a los animales. $3^{\mathrm{a}}$ ed. Vol 3 . Washington: OPS. 413 p.

2. Appleford PJ, Smith JE. 2000. Strain and stage specific variation in Toxoplasma gondii antigens. Int $\mathbf{J}$ Parasitol 30: 1187-1191.

3. Barberan M, Marco JC. 1997. Patogenia, cuadro clínico y lesional en toxoplasmosis-neosporosis. Rev Aula Veterinaria OVIS 52: 35-48.

4. Blewett DA, Bryson CE, Miller JK. 1983. Studies of antibody titers in experimentally induced ovine Toxoplasmosis. Res Vet Sci 34: 163-166.

5. Blood DC, Radostitis OM, Henderson JA. 1992. Medicina veterinaria. $6^{\mathrm{a}} \mathrm{ed}$. México: Interamericana. $851 \mathrm{p}$.

6. D'Angelino JLD, Ishizuka MM. 1986. Toxoplasmose avaliação da prevalência da infecção toxoplasmática nos rebanhos pela prova de imunofluorescência indireta e hemaglutinação. Bol Ofic Sanit Panam 100: 634-645.

7. Dubey JP, Lappin MR. 2000. Toxoplasmosis y neosporosis. En: Green CE (eds). Enfermedades infecciosas en perros y gatos. $2^{\mathrm{a}}$ ed. México: Mc Graw Hill Interamericana. p 542-560.
8. Freyre A, Bonino J, Falcon J, Castells D, Correa O, Casaretto A. 1999. The incidence and economic significance of ovine toxoplasmosis in Uruguay. Vet Parasitol 81: 87-90.

9. Gómez FR, Chávez A, Casas E, Serrano $E$, Cárdenas $O$. 2003. Determinación de la seroprevalencia de Toxoplasma gondii en alpacas y llamas en la estación experimental del INIAPuno. Rev Inv Vet, Perú 14: 49-53.

10. Góngora M. 1992. Prevalencia de anticuerpos contra Toxoplasma gondii en las comunidades alpaqueras de Vilcallamas, Bajo Llallahua, Huanacayama, Llusta. Tesis de Médico Veterinario y Zootecnista. Puno: Univ. Nacional del Altiplano. $47 \mathrm{p}$.

11. Gorman T, Arancibia JP, Lorca M, Hird D, Alcaino YH. 1999. Seroprevalence of Toxoplasma gondii infection in sheep and alpacas (Lama pacos) in Chile. Prev Vet Med 40: 143 149.

12. [INRENA] Instituto Nacional de Recursos Naturales. 2000. Perú: áreas naturales protegidas. Lima: INRENA, Ministerio de Agricultura. $230 \mathrm{p}$.

13. Kenneth K, Sander C. 1998. Modern epidemielogy. $2^{\text {nd }}$ ed. Rothman K, Greenland S. Modern epidemiology. $2^{\text {nd }}$ ed. Philadelphia: Lippicott-Raven. 752 p.

14. Leguia G, Samamé H, Guerrero C, Rojas, Núñez M. 1988. Prevalencia de anticuerpos contra Toxoplasma gondii en alpacas. Rev Camelid Sudamer 6: 19-22.

15. Luzon M, Alonso A, Quintanilla GA. 1997. Etiología y biología. ToxoplasmosisNeosporosis. Rev Aula Veterinaria OVIS 52: 11-31.

16. Mackie MJ, Alvin GF, Pallister P. 1971. Study to determine the causal relationship of toxoplasmosis to mental retardation. Am J Epidem 94: 215-244.

17. Miguel O. 1982. Técnicas de amostragem para exames laboratoriais. Hyg Alim 1: 413-415. 
18. Rojas M, Lobato I, Moltalvo M. 1989. Prevalencia de Toxoplasma gondii en camélidos sudamericanos. En: Res. XII Reunión Científica Anual Asoc Peruana Prod Anim. Lima, Perú. p 67.

19. Sumar, J, Huanca T. 1988. Glosario de términos utilizados en crianza de alpacas y llamas. Bol Téc IVITACICCS No 5.44 p.
20. Tenter AM, Heckeroth AR, Weiss LM. 2000.Toxoplasma gondii: from animals to humans. Int J Parasitol 30: 1217-1258.

21. Vidal L. 1990. Prevalencia de anticuerpos contra Toxoplasma gondii en cabras de la provincia de Lima. Tesis de Médico Veterinario. Lima: Facultad de Medicina Veterinaria, Univ. Nacional Mayor de San Marcos. 41 p. 